\title{
CRYOGENIC HARDENING AND ITS EFFECTS ON PROPERTIES OF AN AEROSPACE ALUMINIUM ALLOY
}

\author{
Sachin S S
}

\begin{abstract}
Cryogenic Hardening is supplementary process to conventional heat treatment process. In this process the materials are deep freeze to cryogenic temperature (below $-150^{\circ} \mathrm{C},-238^{\circ} \mathrm{F}$ or $123 \mathrm{~K}$ ). It increases the strength and durability of the materials being treated, relieve stress, create a more uniform material and micro smooth surface.

During the process of deep cryogenic hardening, austenite is transformed into martensite, which then tempered to change unto tempered martensite. In addition small carbide particles called eta carbides are precipitated out. This greatly reduces the residual stress and promotes the "Micro Smoothing" of the surface.

There are many applications for different materials, which can be treated. The strength of the material actually increases after the process. The molecular structure is "filled-in" increases the strength of the material. Also the material will not be damaged and it will retain its shape.

Cryogenic hardening is one time irreversible, permanent process. It's a "through" process not a surface treatment which reduces the abrasive wear, relieves internal stress minimizes the susceptibility to micro cracking due to shock forces, lengthens the life and increases the performance. Cryogenically treated pieces are also less susceptible to corrosion. In fact, in the case of drill bits or blades, not only the sharpness will last longer, but also be able to sharpen more times with less removal of material. Each sharpening demonstrates the benefits of hardening.

Keywords - Cryogenic Hardening, heat treatment, austenite, martensite, residual stress, carbide particles
\end{abstract}

\section{INTRODUCTION}

Heat treating is what gives metals its hardness as well as its toughness, wear resistance and ductility. Even performed properly, heat treating cannot remove all of the retained austenite (large, unstable particles of carbon carbide) from steel. Proper heat treating is a key part in increasing a part's toughness, durability, wear resistance, strength and hardness.

The beneficial changes that occur as a result of the heat treat process do not actually take place during the heating, but, rather from the cooling or "quenching" from the high temperature. The benefits of the quench do not stop at room temperature, as many alloys will continue to show significant improvements if the quench temperature is reduced further to subzero levels approaching absolute zero. While it is impossible to actually achieve $0 \mathrm{~K}$ or $273^{\circ} \mathrm{C}$, (a molecular zero movement state that eliminates all stress).

Hence to reduce the amount of retained Austenite in the metals they need to be cooled below room temperature. This is where cryogenic hardening comes into picture, cryogenic temperatures i.e. below $-150^{\circ} \mathrm{C},-238^{\circ} \mathrm{F}$ or $123 \mathrm{~K}$ are very efficient and cost effective in increasing dimensional stability, increasing wear resistance and performance of most metals and alloys by reducing austenite content of metals and alloys.

Some of the benefits of cryogenic hardening include longer part life, less failure due to cracking, improved thermal properties, better electrical properties including less electrical resistance, reduced coefficient of friction, less creep and walk, improved flatness, and easier machining.

\footnotetext{
${ }^{1}$ Department of Mechanical Engineering Vidyavardhaka College of Engineering, Mysuru-02, Karnataka, India
} 


\section{II.DEFINITION}

Cryogenic Hardening A cryogenic hardening is the process of treating work pieces to cryogenic temperatures (below $-150^{\circ} \mathrm{C},-238^{\circ} \mathrm{F}$ or $123 \mathrm{~K}$ ) to remove residual stresses and improve wear resistance on steels by transforming all the austenite into martensite.

\section{HISTORY}

In the past toolmakers would bury components in snow banks for weeks or even months to improve wear resistance. Castings were always left outside in the cold for months or years to age and stabilize. Swiss watchmakers noticed that extreme cold changed the properties of their metal clock parts for the better. They would store them in cold caves and let them freeze during the winter. Because of the secret use of cold treating metals and the resulting increase in watch quality lifted the Swiss watch making to mystic levels.

1930s German records tell of aircraft engine manufacturers testing cryogenics on their products with some success. During World War II American bomber manufacturers used this method of cold tempering to stress relieve aluminum superstructures. This allowed the airplanes to be made from thinner materials of lesser weight. This allowed airplanes to carry heavier ammunition and bomb loads. Increasing the bomb load dramatically increased the effectiveness of the airplanes.

Today cryogenic tempering is used to some degree in many industries. Its positive effects are not just limited to metals. They include nylons and other plastics, lighting, high voltage/amperage electrical systems, soldered connections, computer memory, circuit boards and components, well drilling, machining processes, casting and forging, ceramics, farming, transportation fleets, construction, excavation, etc.

\section{PROCESSES IN CRYOGENIC HARDENING}

1. Lowering the temperature of the object (RAMP DOWN).

2. Holding the temperature low (SOAK).

3. Bringing the temperature back up to room temperature (RAMP UP).

4. Elevating the temperature to above ambient (TEMPER RAMP UP).

5. Holding the elevated temperature for a specific time (TEMPER HOLD).

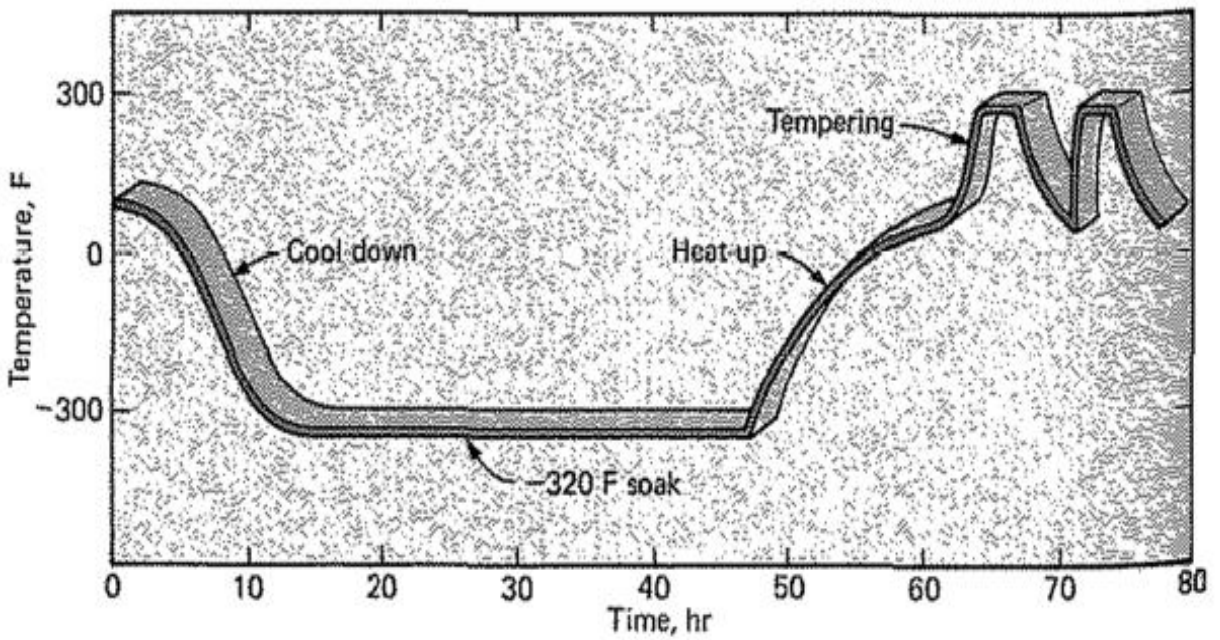

Figure1. Stages in cryogenic hardening

1. RAMP DOWN: Lowering the temperature of the object.

A typical cryogenic cycle will bring the temperature of the part down to $-300^{\circ} \mathrm{F}$ over a period of six to ten hours. This avoids thermally shocking the part. There is ample reason for the slow ramp down. Assume if an object is dropped in a vat of liquid nitrogen. The outside of the object wants to become the same temperature as the liquid nitrogen, which is near $-323^{\circ} \mathrm{F}$. The inside wants to remain at room temperature. This sets up a temperature gradient that is very steep in the first moments of the parts exposure to the liquid nitrogen. The area that is cold wants to contract to the size it would be if it were as cold as the liquid nitrogen. The inside wants to stay the same size it was 
when it was room temperature. This can set up enormous stresses in the surface of the part, which can lead to cracking at the surface. Some metals can take the sudden temperature change, but most tooling steels and steels used for critical parts cannot.

2. SOAK: Holding the temperature low.

A typical soak segment will hold the temperature at $-320^{\circ} \mathrm{F}$ for some period of time, typically eight to forty hours. During the soak segment of the process the temperature is maintained at the low temperature. Although things are changing within the crystal structure of the metal at this temperature, these changes are relatively slow and need time to occur. One of the changes is the precipitation of fine carbides. In theory a perfect crystal lattice structure is in a lowest energy state. If atoms are too near other atoms or too far from other atoms, or if there are vacancies in the structure or dislocations, the total energy in the structure is higher. By keeping the part at a low temperature for a long period of time, we believe we are getting some of the energy out of the lattice and making a more perfect and therefore stronger crystal structure

3. RAMP UP: Bringing the temperature back up to room temperature

A typical ramp up segment brings the temperature back up to room temperature. This can typically take eight to twenty hours. The ramp up cycle is very important to the process. Ramping up too fast can cause problems with the part being treated. Think in terms of dropping an ice cube into a glass of warm water. The ice cube will crack. The same can happen.

4. TEMPER RAMP UP: Elevating the temperature to above ambient A typical temper segment ramps the temperature up to a predetermined level over a period of time. Tempering is important with ferrous metals. The cryogenic temperature will convert almost all retained austenite in a part to martensite. This martensite will be primary martensite, which will be brittle. It must be tempered back to reduce this brittleness. This is done by using the same type of tempering process as is used in a quench and temper cycle in heat treat. We ramp up in temperature to assure the temperature gradients within the part are kept low. Typically, tempering temperatures are from $300^{\circ} \mathrm{F}$ on up to $1100^{\circ} \mathrm{F}$, depending on the metal and the hardness of the metal.

5. TEMPER HOLD: Holding the elevated temperature for a specific time.

The temper hold segment assures the entire part has had the benefit of the tempering temperatures. A typical temper hold time is about 3 hours. This time depends on the thickness and mass of the part. There may be more than one temper sequence for a given part or metal. We have found that certain metals perform better if tempered several times.

\section{MICROSTRUCTURAL CHANGES IN MATERIAL}

Cryogenic processing makes changes to the structure of materials being treated, depending on the composition of the material it performs three things:

1. Conversion of retained austenite into martensite.

2. Fine Carbide Precipitation.

3. Stress relieves

\section{CONVERSION OF RETAINED AUSTENITE INTO MARTENSITE}

In many steels, the transformation of austenite to martensite is complete when the object reaches room temperature. Subsequent cooling to a lower temperature can cause additional transformation of the soft austenite to hard martensite. However, it is possible also to transform all (or nearly all) of the retained austenite in the steel by appropriate elevated temperature tempering treatments that carry the added benefit of reducing the brittleness of the martensite. Cryogenic hardenings can produce not only transformation of retained austenite to martensite, but also can produce metallurgical changes within the martensite. The martensitic structure resists the plastic deformation much better than the austenitic structure, because the carbon atoms in the martensitic lattice "lock together" the iron atoms more effectively than in the more open-centered cubic austenite lattice.

\section{FINE CARBIDE PRECIPITATION}


Cryogenic hardening of high alloy steels, such as tool steel, results in the formation of very small carbide particles dispersed in the martensite structure between the larger carbide particles present in the steel. The small \& hard carbide particles within the martensitic matrix help support the matrix and resist penetration by foreign particles in abrasion wear.

\section{STRESS RELIEVES}

Because austenite and martensite have different size crystal structures, there will be stresses built in to the crystal structure where the two co-exist. Cryogenic processing eliminates these stresses by converting most of the retained austenite to martensite. The densification process leads to an elimination of vacancies in the lattice structure by forcing the material to come to equilibrium at $-320^{\circ} \mathrm{F}$ and lowering the entropy in the material. Besides, there is some amount of grain size refinement and grain boundary realignment occurring in the material.

\section{EFFECT ON ALUMINIUM ALLOY}

Aluminium alloys have long been of interest to the aerospace community, due to their modest specific strength, ease of manufacture, and low cost. Fusion welding is a common method of joining these alloys. However, such techniques can generate defects and high residual stresses. Defects are detected with standard nondestructive evaluation (NDE) techniques. However, residual stresses may generate cracks following proof testing, adding significant costs and schedule delays as repair, inspection, and proof cycles must be repeated.

Methods are continually being sought to improve the weldability of A1 alloys for aerospace applications. At MSFC, attempts are being made to determine how cryogenic treatment affects residual stress, tensile strength, hardness, high cycle fatigue (HCF), and SCC resistance. Reports published in the United States and Europe suggests that cryogenic treatment may have the potential to relieve residual stress without sacrificing tensile strength. Treating tool steels at a low temperature near $-320 \mathrm{~F}(-196$ "C) may result in improved mechanical properties, wear resistance, dimensional stability, and tool life. Recent claims have also been made that cryogenic treatment can improve the material properties of copper, high-temperature alloys, carbides, plastics, and composite materials.

\section{EXPERIMENTAL PROCEDURES}

This study used rolled plates with a thickness of 1.85 inch $(4.7 \mathrm{~cm})$. The material was solutionized and stretched $3 \%$ at ambient temperature. Variable Polarity Plasma Arc (VPPA) welding was conducted with the weld bead perpendicular to the rolling direction. As-welded and cryogenically treated weld specimens were then prepared to allow comparison of test results. Residual stress was measured before and after cryogenic treatment.

The Bragg law states:

$\mathrm{n} \beta=2 \mathrm{~d} \sin \theta$

where $\mathrm{n}$ is an angle denoting the order of diffraction, $\mathrm{h}$ is the $\mathrm{x}$-ray wavelength, $\mathrm{d}$ is the lattice spacing of crystal planes, and 8 is the diffraction angle. These measurements allow the residual stress state to be evaluated. Here, the $\mathrm{X}$-ray diffraction method was used to calculate the $\mathrm{d}$ spacing by measuring the shift of reflected angle $\theta$. Tensile tests were performed at ambient temperature using round specimens. SCC specimens were tested in the short transverse (ST) orientation at 50\% and $75 \%$ of yield strength. Three specimens were tested for each condition in a $3.5 \% \mathrm{NaCl}$ alternate immersion solution per ASTM G44. Unstressed specimens were removed for tensile testing after exposures of various durations.

\section{RESULTS \& DISCUSSION}

\section{RESIDUAL STRESS ANALYSS}

As-welded specimens contained significant amounts of residual stress near the fusion line in the heat affected zone (HAZ). Cryogenically treated specimens showed residual stress reductions of up to $12 \mathrm{ksi}$ in the HAZ. Figure 2 shows no significant changes in the weld bead, fusion line, or parent metal. 


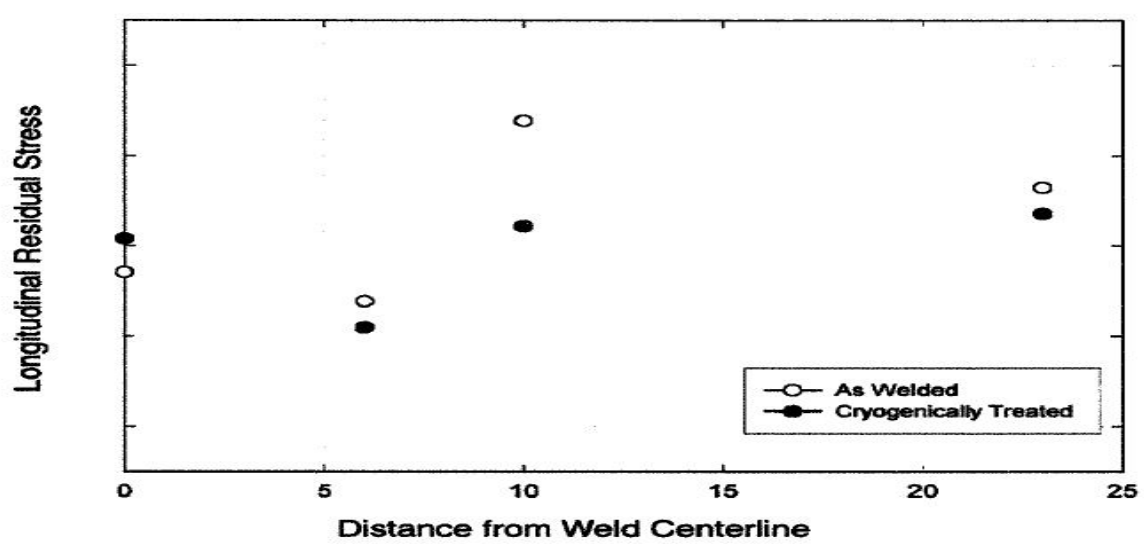

Figure2. Longitudinal residual stress across a VPPA welded panel

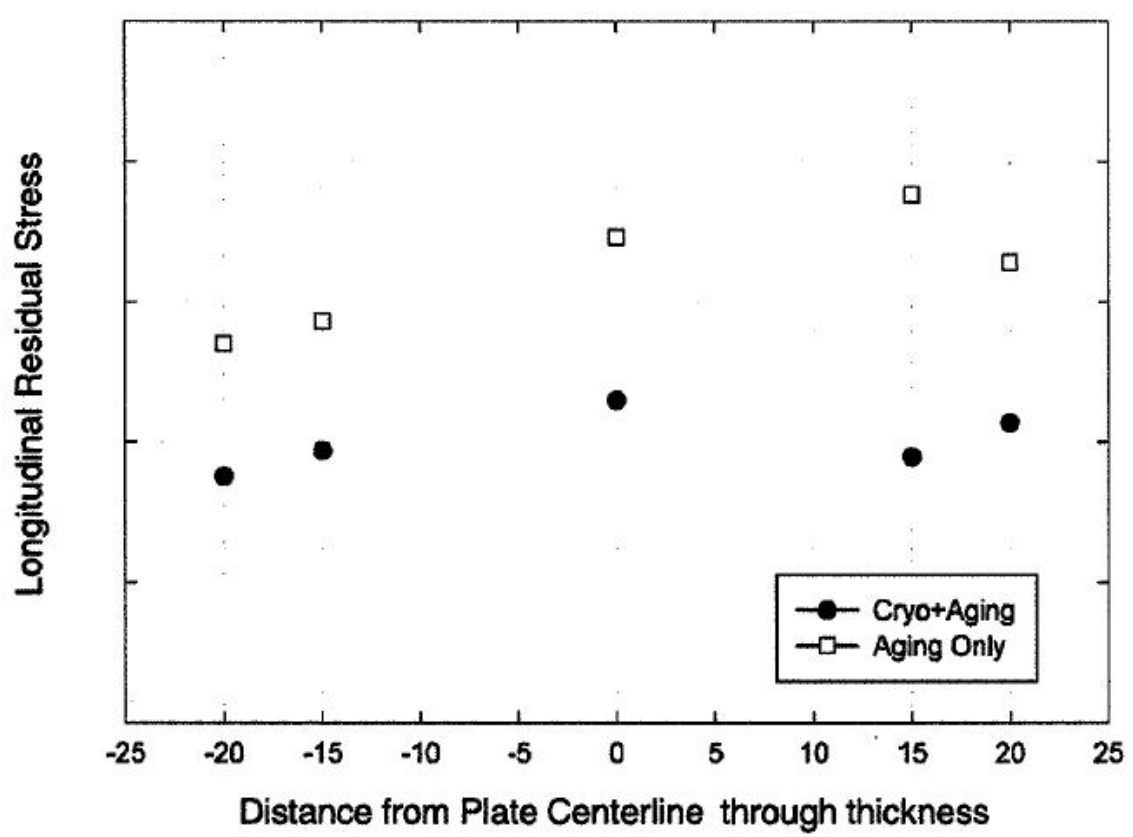

Figure3. Residual stress profiles for rolled plate with a thickness of $1.85 \mathrm{inch}(4.7 \mathrm{~cm})$, with and without cryogenic treatment

\section{TENSILE AND HARDNESS TESTS}

Average hardness increased for parent metal that was artificially aged and then subjected to cryogenic treatment. No significant differences were seen in tensile strength for as-welded and cryogenically treated specimens.

\section{HIGH CYCLE FATIGUE ( HCF ) TESTS}

HCF testing was performed at ambient temperature for as-welded and cryogenically treated specimens. 


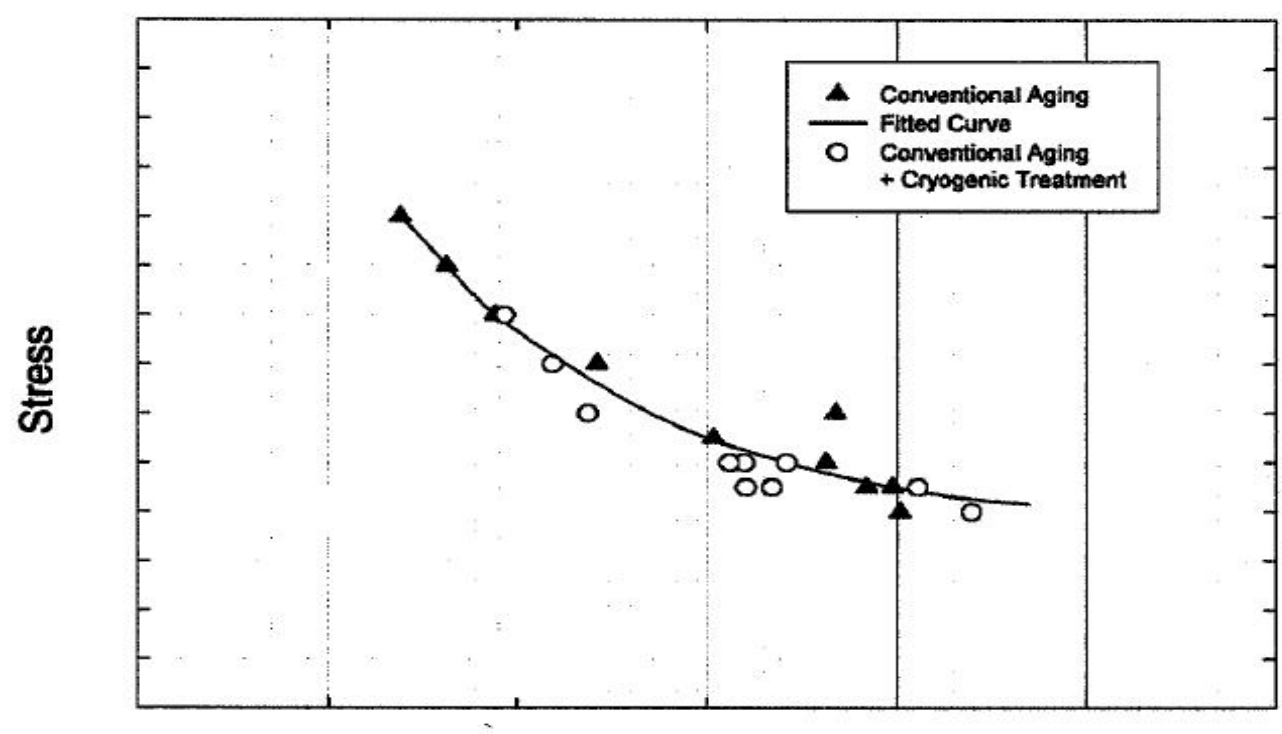

Number of Cycles

Figure4. HCF strength

\section{STRESS CORROSION CRACKING ( SCC ) TESTS}

\begin{tabular}{|c|c|c|c|c|}
\hline Specimen Condition & $\begin{array}{l}\text { Stress } \\
\text { Condition(\% YS) }\end{array}$ & Failure Ratio & $\begin{array}{l}\text { Highest Residual } \\
\text { Stress in HAZ }\end{array}$ & Days to Failure \\
\hline \multirow[t]{2}{*}{ As Welded } & 50 & $1 / 3$ & \multirow[t]{2}{*}{$23.9 \mathrm{ksi}$} & 65 \\
\hline & 75 & $2 / 3$ & & 3,6 \\
\hline \multirow{2}{*}{$\begin{array}{l}\text { Cryogenically } \\
\text { Treated }\end{array}$} & 50 & $0 / 3$ & \multirow[t]{2}{*}{$12.2 \mathrm{ksi}$} & -- \\
\hline & 75 & $2 / 3$ & & 22,84 \\
\hline
\end{tabular}

Table 1 shows significant improvements in SCC lives for cryogenically treated specimens.

\section{CONCLUSION}

The following results were observed for this particular A1 alloy after cryogenic treatment:

1. Residual stress was reduced by up to $12 \mathrm{ksi}$ in the HAZ of weld specimens and by up to $9 \mathrm{ksi}$ in parent metal.

2. Significant improvements in SCC performance were seen for weld specimens.

3. Minor increases in tensile strength and hardness were noted for parent metal.

4. No significant changes were found in tensile properties for weld specimens or in fatigue properties for parent metal.

\section{REFERENCES}

[1] Introduction to Cryogenic Engineering G. Perinić, G. Vandoni, Niinikoski, CERN

[2] Collins, D.N. "Cryogenic Treatment of Tool Steels," Advanced Materials \& Processes, 154: 6 (December 1998): 23-27.

[3] Kamody, D.J. "Using Deep Cryogenic to Advantage," Advanced Materials \& Processes, 154:4 (October 1998): 215-218.

[4] Gary, J. "A Review of Deep Cryogenic Treatment of Steel." Spring 1999. Department of Mechanical Engineering, University of Texas at Austin. <http://ccwf.cc.utexas.edu/-jwgary/cryo/titleehtml. Accessed April 1999.

[5] Gillin, J.P. "Cryogenically Treated Electrical Contacts." US Patent No. 5442929, 1995.

[6] Brunson, R.W. "300 Below, Inc." Home page. <www.300below.com>. Accessed April 1999.

[7] Effect of cryogenic treatment on the mechanical and microstructural properties of Aluminiun Alloys, by PAVAN.K.M, SACHIN.L.S, MAYUR.S, CHANDRASHEKAR.A, B.S.AJAYKUMAR

[8] Effect of Cryogenic Treatment on Various Materials: A Review,Pradeep Joshi, Jaspreet Singh, Prashant Dhiman, Hirendra Shekhar, Viranshu Kumar 